\title{
360-DEGREE EVALUATION REVIEW APPLIED IN TOP-LEVEL EDUCATION
}

\author{
Vázquez Cid de León Carlos \\ carlosvazquezc@mixtecto.utm.mx \\ Montesinos González Salvador ${ }^{1}$ \\ carlosvazquezc@mixtecto.utm.mx \\ Espejo Martínez Abraham \\ Faculty of Accounting and Administration \\ Autonomous University "Benito Juárez" of Oaxaca \\ Av. Universidad S/N. Ex-Hacienda 5 Señores, Universidad, Universitaria Uabjo, \\ Oaxaca de Juárez, Mexico, 68120 \\ aem@usa.com \\ Castañeda Martínez Evelio Erick \\ came980604@ndikandi.utm.mx \\ Martínez Martínez Rigoberto Corby ${ }^{1}$ \\ ankorby@gmail.com \\ ${ }^{1}$ Institute of Industrial and Automotive Engineering \\ University of Technology of the Mixteca \\ Carretera a Acatlima Km. 2.5, Acatlima, \\ Huajuapan de León, Oax., Mexico, 69000
}

\begin{abstract}
This research paper aims to find and show what was written about the 360 degree assessment, applied to students and university professors. It was found, that the application of this method in medical students is dominant since in this profession not only the accumulation of acquired knowledge, but also the human quality, and the skills they can develop, does not matter. However, in the medical sector today there is a great tension to maintain an excellent service and that has quality in the full extent of the word; in most of the reviewed articles one of the best advantages, shown in the 360 degree evaluation, is that given its nature, it can be used to improve the quality of those, evaluated by speaking from bosses, colleagues, subordinates and clients, as long as the evaluation is done in a proper, honest and well-organized way you get benefits the same as the authors of different works describe them as advantages and disadvantages. The research objective was achieved and a table is provided with the main works, dating from 2013 to 2019, with the aim of providing an update of this topic in 2020.
\end{abstract}

Keywords: 360-degree feedback, multi-evaluator feedback, 360-degree evaluation, applied, universities.

DOI: $10.21303 / 2504-5571.2020 .001313$

\section{Introduction}

Higher education institutions often perform performance assessments, looking for direct benefits for those evaluated and with it for their organization, so these assessments must be done precisely in order to avoid making errors of measuring indicators that are not consistent with respect to the substantive competencies and functions of interest $[1,2]$.

This research paper addresses the latest, written in terms of the assessment of competencies by the 360-degree feedback method, which consists of an evaluation, involving the employee, their peers, bosses and subordinates, using forms or questionnaires that provide performance information and competencies of interest, this with the ultimate goal of developing people professionally through training $[3,4]$. This method has been incorporated into higher-level schools, because there is a concern that quality is well defined in the policies of educational institutions so that people can access a proven quality education [5]. 
The overall goal of this article is to know the state of art and show the available evidence [6] of the assessment methods, applied to teachers and higher education students, specifically using 360-degree feedback or multi-evaluator feedback (MRF).

\section{Theoretical framework}

\section{1. What is the 360-degree evaluation?}

Says [7, 8] 360-degree evaluation or also known as multi-source feedback is an evaluation that is performed by both evaluators of professional behavior as well as by residents, who are given a high degree of reliability. Likewise, it is known, that this evaluation is a process that helps a person to collect a feedback of their respective performance in specific competencies with those, with whom he/she locks for his/her respective analysis [9]. It should be noted, that to make a 360-degree assessment, it must be taken very seriously since when working with the staff, it can be emotionally damaged, because performing the evaluation can touch delicate points, of which can hurt the feeling or self-esteem, depending on the case of each evaluation (Fig. 1).

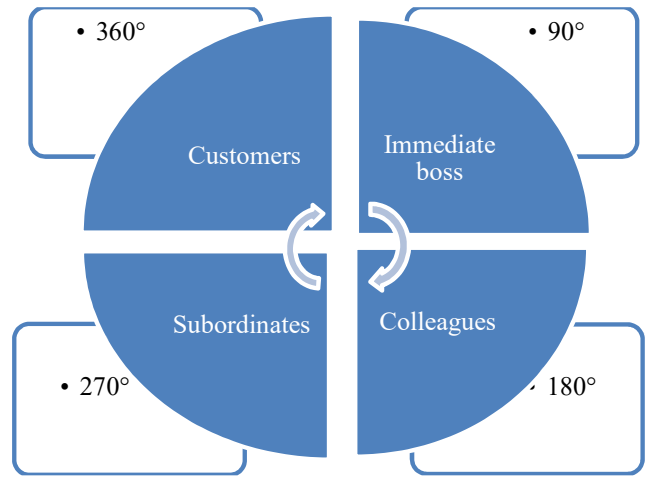

Fig. 1. Process, used for bibliographic review Source: [10]

\section{2. Advantages and disadvantages of 360-degree evaluation}

One of the main advantages that you have when making this type of evaluation is that the feedback has different perspectives, and with this you can achieve integrate different points of view, allowing to increase the personal development of the person evaluated [11]. This evaluation allows to measure personal performance, as well as competencies and behaviors, also facilitates the design of development programs, therefore evaluation is a good way to obtain opinions from different collaborators regarding the performance of someone in particular, which allows the improvement of performance $[12,13]$. In other words, this type of evaluation promotes transparent information, because collaboration at all hierarchical levels is indispensable since the evaluation involves many employees, likewise 360 degree motivates employees to growth and continuous improvement, because when evaluated, a degree of trust is created between the evaluators and those evaluated whenever they are carried out with total honesty.

The disadvantages that are to deal within the 360-degree assessment occur when evaluators tend to issue assessments, based on prejudice and not on tangible elements and observable behaviors, so often more affinity or interpersonal relationship is measured more than competition [9]. It also usually happens, that if the evaluation is aligned to some kind of note or score, sometimes alliances are created between evaluators and the evaluated, thus impacting the reliability of the evaluation [9]. Evaluating another in your performance needs some training in using very simple and intuitive tools [14]. One may consider that it is a problem that the evaluator does not take seriously enough the evaluations that it has the task entrusted to perform, in addition it may happen that the evaluator does not have enough information of the position or person to evaluate, it is also often the case, that the evaluator uses unclear and ambiguous language [11]. In education it is often the case, that the student runs rumors saying that the feedback assessment counts in his final grade $[9,15,16]$. 


\section{Research objective}

To find and show the last written 360 degree evaluation, applied to students and university professors, in order to review the literature and expose some of the main investigated papers as well as the pros and cons of the 360 degree evaluation.

\section{Methodology}

The research carried out was exploratory, descriptive and transactional, which sought to establish the current state of art of the 360-degree assessment, applied to teachers and engineering students of the higher level. For the literature review, the research methodology of [9, 17], recommended for this type of research, should select the field of study, avoiding extending the topic much, as well as not reducing it too much, since you can make the mistake of not considering important information, because of much reduction in the subject, the search was done in the databases of Scopus.com under the search criterion "360-degree assessment applied to universities". The main source of information was considered, scientific articles, since they contain updated and modern information, the topic of research was limited to conducting bibliographic searches, comprising the period 2012-2020, but no secondary literature was excluded to help better understand the concepts and definitions of the current topic. The search for information was carried out in two stages, the first, consisted in the automatic selection of scientific articles, this from the design of search criteria that allowed Scopus.com filter articles, related to the 360 -degree evaluation and universities or higher education schools. The applied methodology of Medina-Lopez can be summarized in Fig. 2.

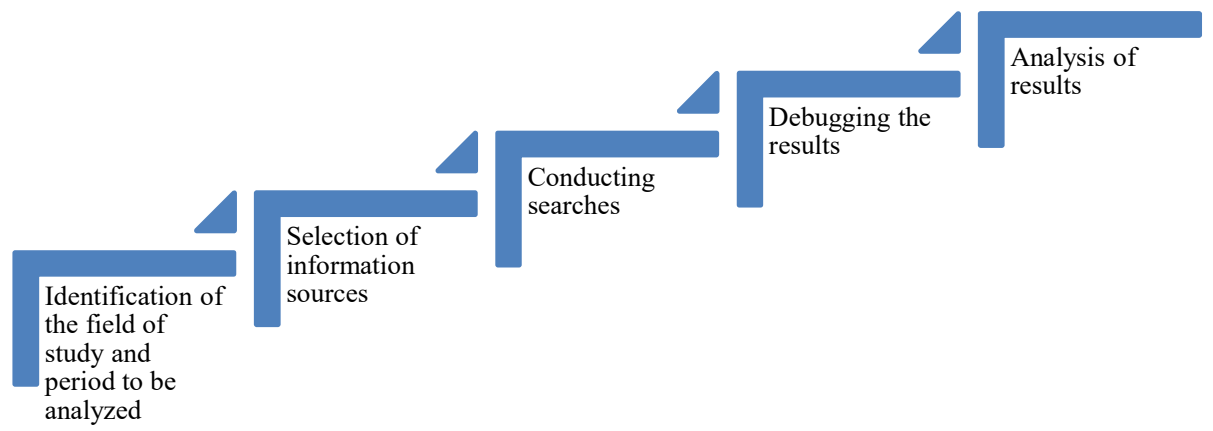

Fig. 2. Process, used for bibliographic review Source: Medina-Lopez, 2010

Initially the first searches were carried out in the Spanish language, however research articles, written during the period 2012-2020, were obtained. The seven search criteria, used in Scopus.com databases, are as follows:

1. 360-degree assessment in higher education.

2. 360-degree assessment of university staff performance.

3. Feedback assessment 360-degree applied to universities.

4. Feedback from multiple sources at university.

5. 360-degree feedback at college.

6. "360-degree" feedback at universities

7. 360-degree feedback application.

Because the criteria in Spanish search yielded very few results, it was necessary to translate them into the English language, it was chosen to consider only the last four search criteria since a greater number of articles, related to the subject, were obtained, so it was finally worked with criteria 4, 5, 6 and 7 as shown in Table 1).

These four search criteria were able to filter a total of 80 scientific articles, which were stored in folders according to the criteria used. Of the $100 \%$ of articles, found using automatic search, $12 \%$ corresponded to criterion $4,36 \%$ to criterion $5,31 \%$ to criterion 6 and $21 \%$ of the articles, found to you under criterion 7 (Fig. 3). 
Table 1

Entered keywords, used for the automatic selection of scientific articles in the database, located in scopus.com.

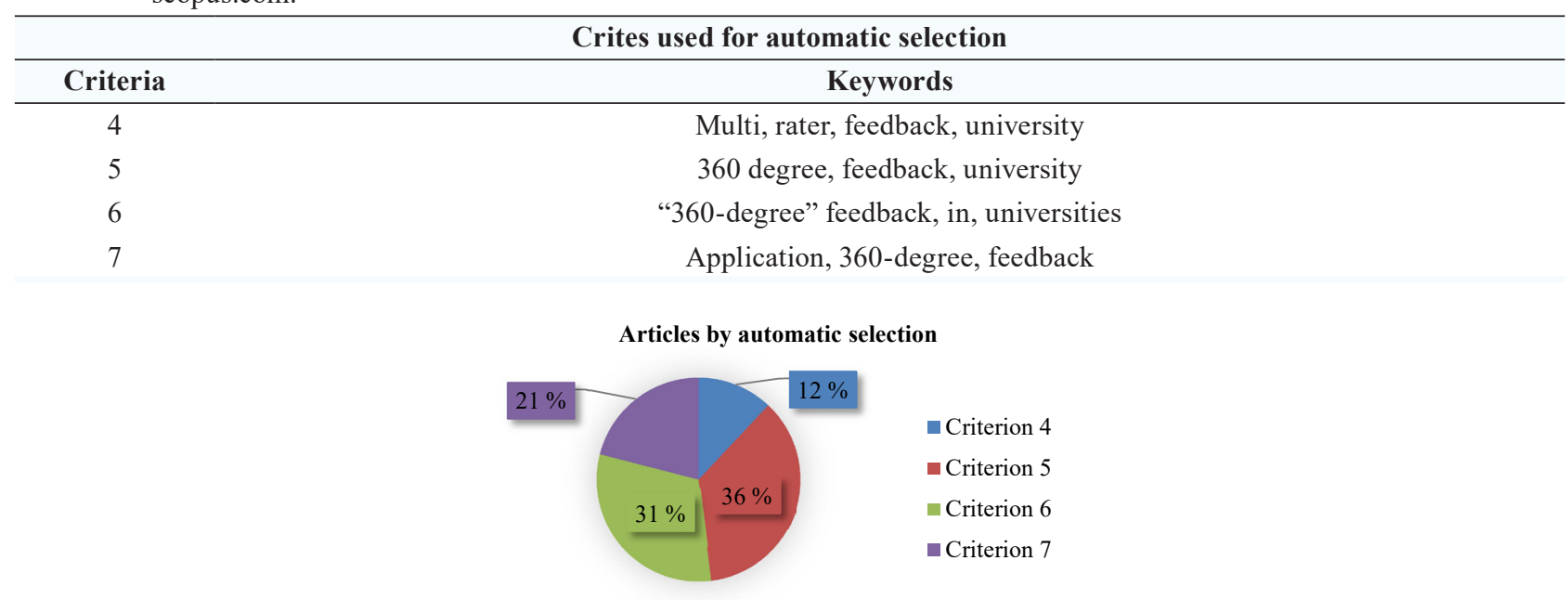

Fig. 3. Graph of the percentage of items, found in automatic selection

In the second stage these articles were given a second filtering, where the researchers used the manual selection, which consisted of the detailed review of the contents of them, it was sought to identify the articles, useful for this research according to [10], for this activity a thorough review of each scientific paper was carried out to identify the objectives of these works, we discarded all those, who did not apply the 360 degree assessment to students or teachers, articles that have developed a method to implement the 360-degree assessment in higher education, we took care of that in the conclusions of the researchers' obtained results, applicable to the institutions, articles were also considered, concluding that the 360-degree assessment was not an appropriate method to be applied in the institutions. In this second stage $2.50 \%$ of the total articles, obtained in stage 1, were obtained for criterion 4, 3.50\% for criterion 5, $6.25 \%$ for criterion 6 and end $1.25 \%$ for criterion 7 (Fig. 4).

Articles by manual selection

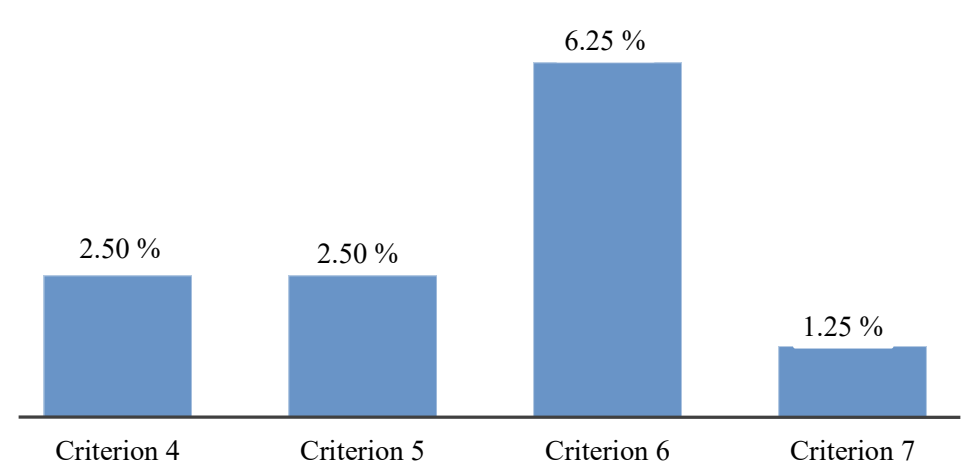

Fig. 4. Total items, found using manual selection, sorted according to the criteria of automatic selection

The articles, obtained in stage 2 of the research, were subjected to a third revision, but this time, in order to synthesize the results from the elaboration of a registration table (Medina-Lopez, 2010), the information, obtained by each scientific article, was recorded.

\section{Results}

Of the $100 \%$ of scientific articles, initially found in stage 1 , only $12 \%$ present relevant information for this research. This percentage of articles covers topics, where 360-degree evaluation 
is evident, not only as a method of evaluation, but as a tool that allows educational institutions to obtain information, related to professionalism, leadership in undergraduate students, methods of leadership teaching, effectiveness of leadership in the professor in addition to communication between a teacher and students $[18,19]$. It also addresses the importance of an evaluation during the teaching-learning process for both the teacher and the student, it is proposed to use methods, such as summative and formative assessment in such a way that it is balanced to improve not only the success of students but also of teachers and university institutions, increasing the quality of education, from the identification of deficiencies of students in a timely manner (Table 2).

Table 2

Literature review

\begin{tabular}{ccccc}
\hline No & Item name & Author(s) & Year & Contribution \\
\hline $\mathbf{1}$ & $\mathbf{2}$ & $\mathbf{3}$ & $\mathbf{4}$ & $\mathbf{5}$ \\
\hline & $\begin{array}{l}\text { A follow-up study on vocational } \\
\text { high school principals' opinions } \\
\text { about 360 degree evaluation } \\
\text { feedback and their leadership ef- } \\
\text { fectiveness and behavior change }\end{array}$ & $\begin{array}{c}\text { Tsai-Feng C. \& } \\
\text { Huei-Chun W. }\end{array}$ & 2019 & $\begin{array}{c}\text { The leadership effectiveness of high school } \\
\text { principals and differences before and after } \\
\text { implementing 360-degree evaluation feedback is } \\
\text { investigated. }\end{array}$ \\
& & $\begin{array}{c}\text { Directors' opinions regarding the 360-degree } \\
\text { assessment and their perceptions of influence on } \\
\text { leadership effectiveness are explored }\end{array}$
\end{tabular}

A 360-degree assessment of teaching effectiveness, using

2 a structured-video recorded, observed teaching exercises for faculty development

Dr. Congeniality: Understanding the Importance of Surgeons' Nontechnical Skills Through $360^{\circ}$ Feedback

Effectiveness of 360o feedback to develop skills in college students

Global Mental Health: Five

5 Areas for Value-Driven Training Innovation

Brandon A., Carla B., Franklin S. Watkins, Julie Williams, Ann Lambros,

Kathryn E. Callahan, Janice Lawlor, Jeff D. Williamson, Kevin P. High \& Hal H. Atkinson

Lanz J. J., Gregory P. J., Menendez M. E., Harmon L

Luis Iván Mayor Silva

Alofs L., Huiskes J.,

User reception of a simple 6 online multisource feedback tool for residents
Catherine P., Alexander C. \& 2016 Milton L.
Horsman M.,

van der Plank L., ten Cate O. 2016

A process is proposed that is convenient and effective to incorporate the analysis of teachers' behaviors and competencies. It describes a novel

2019 technique that uses simulated, video-recorded teaching exercises to compile multidimensional comments to aid in professional development programs

Patient satisfaction and teamwork performance were sought, using the 360-degree assessment to give a better review to the staff.

There was great satisfaction in working with patients and team members as work techniques and patient treatment were improved

The results, obtained in the creation and implementation of an evaluation and development instrument from the merger of the 360-degree assessment and rubrics, are presented and analyzed, which improves the effectiveness in the performance of the competence of communication between college students

Interdisciplinary discussions are presented to encourage innovation in value-based training, such recommendations improve training, gained through international experiences, as well as training mental health professionals, global

health professionals and social scientists. 360 -degree feedback is made from partners in low-resource settings and observed structured clinical assessments (CSUs) with people from different cultural backgrounds to contribute to the trainings

The 360-degree assessment was implemented in a modern way by doing it online, which gave bet2015 ter results and a fairly significant cost reduction, and was also unveiled as easily accessible and attainable 
Continuation of Table 2

\begin{tabular}{|c|c|c|c|c|}
\hline 1 & 2 & 3 & 4 & 5 \\
\hline 7 & $\begin{array}{l}\text { Using } 360 \text {-degree multi-source } \\
\text { feedback to evaluate profession- } \\
\text { alism in surgery departments: } \\
\text { An Iranian perspective }\end{array}$ & $\begin{array}{c}\text { Yazdankhah A., } \\
\text { Tayefeh Norooz M., } \\
\text { Ahmadi Amoli H., } \\
\text { Aminian A., Khorgami Z., } \\
\text { Khashayar P., Khashayar P. }\end{array}$ & 2015 & $\begin{array}{l}\text { Research areas were incorporated such as: team- } \\
\text { work, interpersonal skills, communication skills, } \\
\text { management skills and clinical decision-making } \\
\text { through the } 360 \text {-degree assessment. } \\
\text { Inconveniences were presented, such as having } \\
\text { faith in the evaluators' will to be fair }\end{array}$ \\
\hline 8 & $\begin{array}{c}\text { Can student self-ratings be com- } \\
\text { pared with peer ratings? A study } \\
\text { of measurement invariance of } \\
\text { multisource feedback }\end{array}$ & $\begin{array}{l}\text { Keng-Lin L., Shih-Li T., } \\
\text { Yu-Ting C. and } \\
\text { Ming-Jung H. }\end{array}$ & 2015 & $\begin{array}{l}\text { Feedback from multiple sources (SPS) or } 360 \text {-de- } \\
\text { gree evaluation was analyzed, seeing if it has the } \\
\text { same meaning in different types of evaluators } \\
\text { and evaluations, making a comparison with } \\
\text { different evaluation instruments }\end{array}$ \\
\hline 9 & $\begin{array}{l}\text { An exploration of teaching } \\
\text { methods, used to develop } \\
\text { leaders. Leadership educators } \\
\text { perceptions }\end{array}$ & $\begin{array}{l}\text { Nathan S. Hartman, } \\
\text { Scott J. Allen \& } \\
\text { Rosanna F. Miguel }\end{array}$ & 2015 & $\begin{array}{l}\text { Exploring how educators can benefit from teach- } \\
\text { ing methods or learning sources, used for leader- } \\
\text { ship development in undergraduate students }\end{array}$ \\
\hline 10 & $\begin{array}{l}\text { A } 360 \text {-Degree Evaluation of the } \\
\text { Communication and Interper- } \\
\text { sonal Skills of Medicine Resi- } \\
\text { dent Physicians in Pakistan }\end{array}$ & $\begin{array}{l}\text { Muhammad T., John B., } \\
\text { Afaq M., Nida S. \& Syeda A. }\end{array}$ & 2014 & $\begin{array}{l}\text { A performance assessment ( } 360 \text {-degree assess- } \\
\text { ment) made known about the importance of } \\
\text { effective communication, as makes emphasis on } \\
\text { how interpersonal skills also play a very import- } \\
\text { ant role in the areas of performance of medical } \\
\text { students, who make their professional stays }\end{array}$ \\
\hline 11 & $\begin{array}{l}\text { A Faculty Toolkit for Forma- } \\
\text { tive Assessment in Pharmacy } \\
\text { Education }\end{array}$ & Margarita V. DiVall. & 2014 & $\begin{array}{c}\text { Several formative assessment strategies are } \\
\text { discussed to evaluate students' learning in the } \\
\text { classroom, laboratory, experience and interpro- } \\
\text { fessional education. } \\
\text { The researcher emphasizes the importance of } \\
\text { creating a culture of evaluation that encloses the } \\
\text { concept of } 360 \text {-degree evaluation in both the de- } \\
\text { velopment of the student's ability and the ability } \\
\text { of a faculty member }\end{array}$ \\
\hline 12 & $\begin{array}{l}\text { Assessing Medical Students' } \\
\text { Performance in Core Competen- } \\
\text { cies, Using Multiple Admission } \\
\text { Programs for Colleges and Uni- } \\
\text { versities: from the Perspective of } \\
\quad \text { Multi-source Feedback }\end{array}$ & $\begin{array}{l}\text { Ji-Tseng F.; Yu-Shien K.; } \\
\text { Chu-Chun C. and } \\
\text { Kuang-Hui Y. }\end{array}$ & 2013 & $\begin{array}{l}\text { They evaluated medical students at Chang Gung } \\
\text { Medical School, using several assessment tools, } \\
\text { including multi-source assessment (MSF), best } \\
\text { known as 360-degree assessment with the inten- } \\
\text { tion of maintaining a relationship with patients } \\
\text { and working effectively with medical teams. }\end{array}$ \\
\hline
\end{tabular}

Once the literature review table is completed, two cases are exposed among the most relevant cases:

$1-[20,21]$ conducted a study to provide evidence-based recommendations from an online survey that seeks to determine among 25 learning sources (knowledge-able activities), which were best suited for leadership development in undergraduate students. Four important learning categories for leadership development were considered as personal growth, conceptual understanding, feedback and skills development [14, 22, 23]. In this study, 360-degree feedback was considered as a source of learning, obtained in the categories of conceptual understanding, feedback, skill development and personal growth, a score of 2.17, 3.37, 2.65 and 3.26 respectively. A score of 5 would mean that respondents agree that the 360-degree evaluation method encourages conceptual understanding and a score of 1 would mean that they do not agree that they encourage such a category, to give an example. Through this study, Hartman concluded that one should not rely solely on one type of source of learning, he believes that teachers through his study will be able to make better decisions in adopting learning sources for the improvement of institutional programs that develop leaders.

2 - [24] The author compares the summative and formative assessments, the first is an evaluation, made at the end of the teaching-learning process and does not allow students to benefit from 
the feedback, given by the teacher until starting a new course, an example of this type of evaluation is the exams that are taken at the end of a course, since with it the teacher must determine whether or not the student meets the necessary knowledge to be able to pass. The formative evaluation on the other hand, is done during the teaching-learning process and is commonly included in class activities. This evaluation is designed to know, what knowledge students possess before and after each session, so the teacher obtains information on the quality of his/her academics and can design strategies to improve them. It is there that [24] proposes to use the 360-degree assessment, because it includes the evaluation of the colleagues of the teacher evaluated, the evaluation of their superiors and the evaluation of the students that can be considered as valid and useful [25], but in the same way may be inaccurate, because a student cannot know the degree of expertise that his/her teacher possesses [26] This can provide more reliable results that tell us, in which areas instructors can improve to improve the quality of the chairs. The proposal is to use the 360 assessment, including the formative assessment in both directions, so that teachers understand, how they can improve during the teaching-learning process, and also so that they can obtain data, on how much information students retain before reaching the summative assessment.

\section{Discussion}

It was found, that $33 \%$ of scientific articles used resources, such as online surveys or taking information from a web or android. It is interesting to note, that even in $2019,67 \%$ of the researches consulted still use the classic 360-degree evaluation form, which is to fill out printed surveys. However, $100 \%$ of reviewed articles mention having captured the information, obtained in electronic spreadsheets. This tells us that the application of the technologies has not yet been fully adopted, one of the main reasons observed, is that there is no technical knowledge, necessary for the correct application of new technologies in the 360-degree evaluation [14, 23, 27, 28] (Fig. 5, 6).

Scientific research that used online surveys

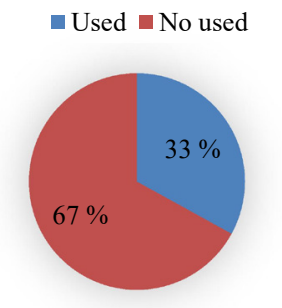

Fig. 5. Distribution of items that use and do not use online surveys

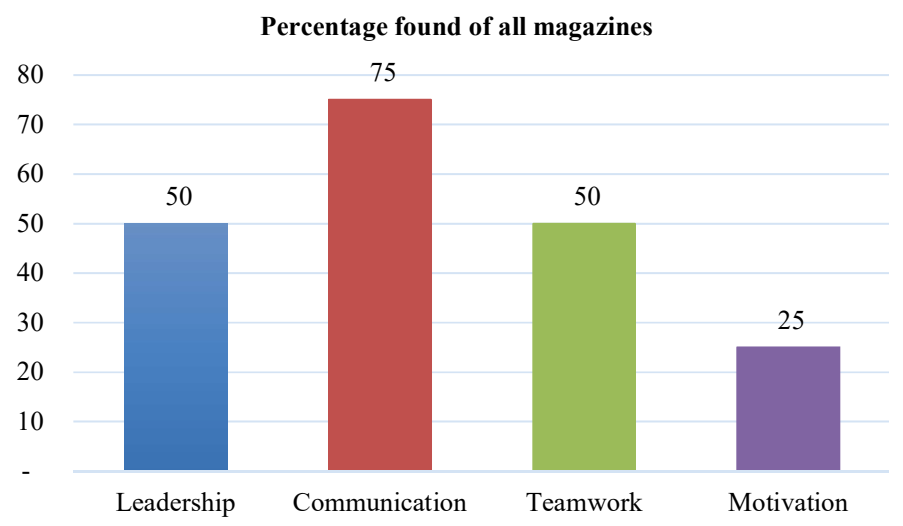

Fig. 6. Results of competency research in scientific articles

Of the revised articles it was found, that the most important competence for researchers was communication with a $75 \%$ presence, because it is seen as fundamental to a good performance of educational institutions, since adequate communication fosters a healthy organizational climate. 
Leadership and teamwork were mentioned equally $50 \%$, which makes sense, as you can't expect to have leaders without a team. Finally, the motivation is not very considered in evaluations, made to teachers and students, it is thought, that this is due to a poor implementation of the evaluations carried out.

\section{Conclusions}

The objective of this research was achieved, because the period from 2012-2020 found that the 360-degree assessment has been largely applied in medical education institutions, no articles were found that applied this method to institutions of an engineering nature, it is considered, that there is an area of opportunity for educational institutions that do not belong to the medical sciences, since there is already a background of application to university education [24]. It is proposed to implement this evaluation tool to improve the educational quality of higher education, seeking the continuous improvement of students and teachers. It was found, that paper surveys continue to be used in the 2019 , which not only means high operating costs, but also means that the results cannot be analyzed quickly. It is proposed to conduct case studies, where the 360-degree assessment is applied, using technologies, such as online surveys, specialized software development and real-time data analysis.

\section{References}

[1] Fang, J.-T., Ko, Y.-S., Chien, C.-C., Yu, K.-H. (2013). Assessing medical students' performance in core competencies using multiple admission programs for colleges and universities: From the perspective of multi-source feedback. Biomedical Journal, 36 (4), 188. doi: http://doi.org/10.4103/2319-4170.113856

[2] Sapién-Aguilar, A., Gutiérrez-Díez, M., Piñón-Howlet, L. Araiza-Zapata, P. (2016). Performance evaluation by 360 degree method and evaluation factors in a Mexican company. Publications, 46, 13-29.

[3] Alles, M. (2005). 360o feedback or 360-degree evaluation. Competency performance: 360-degree evaluationю Buenos Aires: Granica, 141-187.

[4] Jones, C. A., Watkins, F. S., Williams, J., Lambros, A., Callahan, K. E., Lawlor, J. et. al. (2019). A 360-degree assessment of teaching effectiveness using a structured-videorecorded observed teaching exercise for faculty development. Medical Education Online, 24 (1), 1596708. doi: http://doi.org/10.1080/10872981.2019.1596708

[5] Sifuentes Ocegueda, A. T., Hoyos Castellanos, C. A., Cortés García, P. J. (2016). Proposal for a 360-degree performance assessment model for higher education teaching staff. Journal of Science, Technology and Innovation, 3, 197-211.

[6] Vera-Carrasco, O. (2009). How to write review articles. La Paz Medical Journal, 15, 63-69.

[7] Alofs, L., Huiskes, J., Heineman, M. J., Buis, C., Horsman, M., van der Plank, L., ten Cate, O. (2015). User reception of a simple online multisource feedback tool for residents. Perspectives on Medical Education, 4 (2), 57-65. doi: http://doi.org/10.1007/ s40037-015-0173-0

[8] Wood, L., Hassell, A., Whitehouse, A., Bullock, A., Wall, D. (2006). A literature review of multi-source feedback systems within and without health services, leading to 10 tips for their successful design. Medical Teacher, 28 (7), e185-e191. doi: http:// doi.org/10.1080/01421590600834286

[9] Mayor, I., Rodriguez, M. (2014). $360^{\circ}$ feedback and feedforward dynamics for the evaluation and development of emotional intelligence.

[10] Medina-Lopez, C., Marin-Garcia, J. A., Alfalla-Luque, R. (2010). A methodological proposal for the systematic literature review. WPOM-Working Papers on Operations Management, 1 (2), 13-30. doi: http://doi.org/10.4995/wpom.vli2.786

[11] Chiavenato, I. (2011). Performance Assessment. Human Resources Management: The human capital of organizations. Mexico: McGraw-Hill, 222-223.

[12] Parra, M. (2002). La evaluación del desempeño y la gestión de los RRHH. Universidad rafael Belloso Chacín- urbe.

[13] Zuñiga, A. (2006). Evaluación integral de productividad.

[14] Johanna, P., Eudosia, S. (2013). Evaluación de desempeño 360 grados al personal de la carrera de Administración de empresas 2013. Universidad de Cuenca, 55-56. Available at: http://dspace.ucuenca.edu.ec/bitstream/123456789/3540/1/TESIS.pdf Last accessed: 12.06 .2015

[15] Lanz, J. J., Gregory, P. J., Menendez, M. E., Harmon, L. (2018). Dr. Congeniality: Understanding the Importance of Surgeons' Nontechnical Skills Through $360^{\circ}$ Feedback. Journal of Surgical Education, 75 (4), 984-992. doi: http://doi.org/10.1016/j.jsurg. 2017.12.006

[16] Luis, I., Mayor, S. (2016). Effectiveness of 360o feedback to develop competencies in university students. Option, 32, $225-243$. 
[17] Alfalla-Luque, R., Medina-López, C. (2010). Manage beyond the limits of the individual company: An opportunity to gain competitive advantages. Economics and Administration, 1 (2), 114-137. doi: http://doi.org/10.5377/eya.vli2.4353

[18] Tariq, M., Boulet, J., Motiwala, A., Sajjad, N., Ali, S. (2014). A 360-degree evaluation of the communication and interpersonal skills of medicine resident physicians in Pakistan. Education for Health, 27 (3), 269-276. doi: http://doi.org/10.4103/13576283.152188

[19] Hartman, N. S., Allen, S. J., Miguel, R. F. (2015). An exploration of teaching methods used to develop leaders. Leadership educators' perceptions. Leadership \& Organization Development Journal, 36 (5), 454-472. doi: http://doi.org/10.1108/lodj-072013-0097

[20] Hartman, N., Allen, S., Miguel, R. (2015). An exploration of teaching methods used to develop leaders: Leadership educators' perceptions. Leadership \& Organization Development Journal, 36 (5), 454-472. doi: http://doi.org/10.1108/lodj-07-2013-0097

[21] Lee, K.-L., Tsai, S.-L., Chiu, Y.-T., Ho, M.-J. (2015). Can student self-ratings be compared with peer ratings? A study of measurement invariance of multisource feedback. Advances in Health Sciences Education, 21 (2), 401-413. doi: http://doi.org/ 10.1007/s10459-015-9638-5

[22] Conger, J. (1992), Learning to Lead: The Art of Transforming Managers into Leaders. San Francisco: Jossey-Bass, 234.

[23] Cheng, T.-F., Wu, H.-C. (2019). A follow-up study on vocational high school principals' opinions about 360 degree evaluation feedback and their leadership effectiveness and behavior change. Asia Pacific Education Review, 21 (1), 65-81. doi: http:// doi.org/10.1007/s12564-019-09608-x

[24] DiVall, M. V., Alston, G. L., Bird, E., Buring, S. M., Kelley, K. A., Murphy, N. L. et. al. (2014). A Faculty Toolkit for Formative Assessment in Pharmacy Education. American Journal of Pharmaceutical Education, 78 (9), 160. doi: http://doi.org/10.5688/ ajpe789160

[25] Williams, B. C., Pillsbury, M. S., Stern, D. T., Grum, C. M. (2001). Comparison of Resident and Medical Student Evaluation of Faculty Teaching. Evaluation \& the Health Professions, 24 (1), 53-60. doi: http://doi.org/10.1177/01632780122034786

[26] Arreola, R. A. (2000). Common questions concerning student ratings: what 80 years of research tells us. Developing a Comprehensive Faculty Evaluation System. Bolton: AnkerPublishing In, 79-92.

[27] Yazdankhah, A., Tayefeh Norooz, M., Ahmadi Amoli, H., Aminian, A., Khorgami, Z., Khashayar, P., Khashayar, P. (2015). Using 360-degree multi-source feedback to evaluate professionalism in surgery departments: An Iranian perspective. Medical Journal of the Islamic Republic of Iran, 29, 1088-1094.

[28] Kohrt, B. A., Marienfeld, C. B., Panter-Brick, C., Tsai, A. C., Wainberg, M. L. (2016). Global Mental Health: Five Areas for Value-Driven Training Innovation. Academic Psychiatry, 40 (4), 650-658. doi: http://doi.org/10.1007/s40596-016-0504-4 